\title{
Pacientes chagásicos crônicos portadores de disfunção do nódulo sinusal: a presença de anticorpos IgG com ação agonista muscarínica independe da disfunção ventricular esquerda?
}

\author{
Chronic Chagas disease patients with sinus node dysfunction: is the presence of $\operatorname{Ig} G$ \\ antibodies with muscarinic agonist action independent of left ventricular dysfunction?
}

\author{
Maria Beatriz Corrêa de Mello Altschüller ${ }^{1}$, Roberto Coury Pedrosa ${ }^{1}$, \\ Basílio de Bragança Pereira², Wilson Braz Corrêa Filho ${ }^{1}$, Aline Silva de Medeiros ${ }^{3}$, \\ Patrícia Cristina Santos Costa ${ }^{4}$ e Antonio Carlos Campos de Carvalho ${ }^{4}$
}

\begin{abstract}
RESUMO
Estudos mostram que anticorpos IgG agonistas muscarínicos, de pacientes chagásicos, alteram a atividade elétrica de células cardíacas in vitro. Outros consideram sua presença, e a da síndrome do nódulo sinusal, conseqüências da lesão cardíaca progressiva. Objetivou-se avaliar a relação entre os anticorpos e as disfunções nodal e ventricular esquerda, em 65 pacientes chagásicos crônicos divididos em grupo I, composto de 31 pacientes portadores da síndrome do nódulo sinusal, e grupo II, de não portadores. A análise dos dados, pelo modelo log linear, mostrou uma interdependência entre a disfunção do nódulo sinusal e os anticorpos $(p=0,0021)$ e entre a disfunção nodal e a ventricular $(p=0,0005)$, mas não houve relação entre esta última e os anticorpos. Idade e sexo não tiveram infliência sobre as outras variáveis. Chagásicos crônicos com a síndrome do nódulo sinusal têm maior prevalência de anticorpos agonistas muscarínicos, independentemente da presença de disfunção miocárdica.
\end{abstract}

Palavras-chaves: Doença de Chagas. Mimetismo molecular. Síndrome do nódulo sinusal. Receptores muscarínicos. Disautonomia.

\begin{abstract}
Studies have shown that muscarinic agonist IgG antibodies from Chagas disease patients alter the electrical activity of cardiac cells in vitro. Others have considered their presence, along with sinus node dysfunction, to be consequences of progressive cardiac lesions. The aim of this study was to evaluate the relationship between these antibodies and sinus node and left ventricular dysfunction in 65 chronic Chagas disease patients. These patients were divided into group I, composed of 31 patients with sinus node dysfunction, and group II, composed of the patients without this syndrome. Data analysis using the log linear model showed interdependence between sinus node dysfunction and the antibodies $(p=0.0021)$ and between nodal and ventricular dysfunction $(p=0.0005)$. However, no relationship was found between the antibodies and ventricular function. Age and sex did not influence any other variables. The chronic Chagas disease patients with sinus node dysfunction had higher prevalence of muscarinic agonist antibodies, independent of the presence of myocardial dysfunction.
\end{abstract}

Key-words: Chagas' disease. Molecular mimicry. Sinus node dysfunction. Muscarinic receptors. Autonomic dysfunction.

A doença de Chagas é, no Brasil, uma das principais causas de disfunção do nódulo sinusal (DNS). Também conhecida como síndrome do nódulo sinusal, afeta a função nodal de forma intrínseca, devido à miocardite crônica, e extrínseca, pela disfunção autonômica ${ }^{138}$. Esta disautonomia, nem sempre proporcional à idade, à extensão da lesão cardíaca e ao status clínico-funcional, está associada ao maior risco de morte ${ }^{27} 34$.
A patogenia da DNS na doença de Chagas é, provavelmente, a mesma da cardiopatia chagásica crônica (CCC) e ainda permanece motivo de controvérsia, principalmente no que se refere à participação de um mecanismo autoimune em sua gênese $\mathrm{e}^{2035374146}$. Alguns estudos relatam a presença de anticorpos IgG com ação agonista de receptores cardíacos muscarínicos M2 (AcM2), e mostram que eles podem induzir distúrbios na

\footnotetext{
1. Serviço de Cardiologia, Hospital Universitário Clementino Fraga Filho, Universidade Federal do Rio de Janeiro, Rio de Janeiro, RJ. 2. Comissão de Investigação Científica e Faculdade de Medicina, Hospital Universitário Clementino Fraga Filho, Universidade Federal do Rio de Janeiro, Rio de Janeiro, RJ. 3. Coordenação dos Programas de Pesquisa em Engenharia, Universidade Federal do Rio de Janeiro, Rio de Janeiro, RJ. 4: Instituto de Biofísica Carlos Chagas Filho, Universidade Federal do Rio de Janeiro, Rio de Janeiro, RJ. Endereço para correspondência: Dra. Maria Beatriz Corrêa de Mello Altschüller. Serviço de Cardiologia Hospital Universitário Clementino Fraga Filho/UFRJ. Av. Brigadeiro Trompowsky s/n/8 andar, Ilha do Fundão, 21941-680 Rio de Janeiro, RJ.

Telefax: 5521 2562-2618

e-mail: mba@hucff.ufrj.br

Recebido para publicação em: 01/09/2006

Aceito em: 06/11/2007
} 
eletrogênese e na condução do estímulo elétrico in vitro e em modelos animais. Carvalho e cols ${ }^{7}$ induziram bloqueios de condução em corações de coelhos normais, perfundindo-os com soro e fração IgG+ de coelhos cronicamente infectados com o Trypanosoma cruzi, pela técnica de Langendorff. 0 mesmo grupo observou que estes AcM2 exercem sua ação através da ligação a um epítopo na segunda alça extracelular dos receptores muscarínicos M2 cardíacos, os quais tem uma sequiência de aminoácidos homóloga a porção C-terminal da proteína P ribossomal do parasita (mimetismo molecular) ${ }^{81329}$. Em estudos subsequientes, demonstrou-se que o soro e a fração $\operatorname{Ig} \mathrm{G}+$ de pacientes chagásicos crônicos induzem alterações na eletrogênese de corações isolados de coelhos e reduzem, de modo dose-dependente, as amplitudes da contração do miocárdio e da corrente de cálcio, o que justifica seu efeito na contratilidade miocárdica e na condução atrioventricular ${ }^{10} 141829$.

No entanto, também é possível que a produção destes anticorpos seja apenas consequiência da liberação de antígenos teciduais, secundária à lesão do tecido cardíaco, e sua presença seja proporcional à idade, ao grau de disfunção ventricular e ao status clínico do paciente. Liu e cols ${ }^{23}$ relataram a presença de anticorpos ativos, contra receptores cardíacos, em dois modelos distintos de indução de remodelamento ventricular: ligadura de aorta abdominal e o uso de adriamicina. Nos dois modelos, o aparecimento transitório dos anticorpos estava associado, temporalmente, à indução de alterações na forma e função miocárdica. Corroborando esta hipótese, Sgammini ${ }^{40}$ relatou que, no grupo acompanhado por ele, a prevalência da síndrome do nódulo sinusal aumentava com o grau de comprometimento miocárdio. Sendo assim, este estudo tem como objetivo avaliar se a disfunção, ou síndrome, do nódulo sinusal está associada à presença de AcM2, na fase crônica da doença de Chagas, independentemente da presença de disfunção miocárdica, da clínica de insuficiência cardíaca (IC), do sexo e da idade.

\section{PACIENTES E MÉTODOS}

Este estudo foi desenvolvido no Ambulatório de Cardiopatia Chagásica, do Hospital Universitário Clementino Fraga Filho (HUCFF), da Universidade Federal do Rio de Janeiro (UFRJ), e aprovado pelo Comitê de Ética em Pesquisa (CEP) do HUCFF-UFRJ, sob parecer do CEP n ${ }^{0}$. 1004/05, atendendo às Diretrizes Éticas Nacionais e Internacionais para Pesquisa Biomédicas Envolvendo Seres Humanos ${ }^{12}$.

Os dados foram obtidos de forma consecutiva, a longo de 16 anos (de 1990 a 2006), e armazenados no Serviço de Documentação Médica (SDM) do HUCFF. A análise foi retrospectiva, pela revisão das fitas dos exames e dos prontuários dos pacientes. Dentre os 280 pacientes acompanhados, ativamente e regularmente, 69 (amostra estudada) tiveram o sangue coletado para a pesquisa da presença de AcM2 em seus soros. Estes pacientes apresentavam idade entre 34 a 72 anos (média $52,2 \pm 9,3$ anos), diagnóstico sorológico positivo para doença de Chagas (hemaglutinação e imunofluorescência indireta) e estavam afastados da zona endêmica há mais de 20 anos. Eram excluídos os pacientes portadores de outras co-morbidades, como tireoidopatias, hipertensão arterial sistêmica, doença pulmonar obstrutiva crônica, cardiopatias de outras etiologias, alcoolismo, doença imunológica, hematológica ou do sistema nervoso ou qualquer outra doença sistêmica conhecida. Durante a primeira semana de acompanhamento (entre 1990 e 2005), após a confirmação sorológica e a assinatura do termo de consentimento livre esclarecido, todos eram submetidos a uma rotina admissional padronizada. Esta rotina era composta de anamnese, exame físico e laboratorial, avaliação radiológica, eletrocardiografia convencional de repouso (ECG) e coleta de sangue para pesquisa da presença dos AcM2. Neste momento, também eram solicitados ecocardiograma bidimensional com Doppler e Holter de 24 horas, realizados com intervalo entre si de até 30 dias, após três meses de estabilidade clínica dos pacientes.

As dimensões sistólicas e diastólicas de ventrículo esquerdo eram medidas de acordo com as recomendações da Sociedade Americana de Ecocardiografia ${ }^{35}$. A função sistólica global do ventrículo esquerdo era avaliada objetivamente, pelo cálculo da fração de ejeção (FEVE) no modo-M ${ }^{47}$, e subjetivamente ${ }^{2}$. Os pacientes eram considerados como tendo disfunção ventricular caso apresentassem FEVE < 55\% ou qualquer grau de disfunção pela avaliação subjetiva. No entanto, como é frequente a presença de assinergia das paredes do ventrículo esquerdo na cardiopatia chagásica, o que pode causar erros na avaliação objetiva da função ventricular, optou-se por considerar, neste estudo, os dados obtidos pela avaliação subjetiva (como realizado por Amico e $\operatorname{cols}^{2}$ ), sendo a função classificada como normal, leve, moderada ou gravemente comprometida. Todos os exames eram gravados em fitas de vídeo, sendo reavaliados por dois observadores, para o presente estudo. 0 diagnóstico clínico de IC era o mesmo utilizado por Schocken e cols ${ }^{39}$, adaptado do First National Health and Nutrition Examination Survey (NHANES-I).

Os ECG dos pacientes foram reavaliados de acordo com as diretrizes da New York Heart Association ${ }^{35}$, utilizando-se o código de Minnesota, modificado para a cardiopatia chagásica ${ }^{25}$, e os critérios do Consenso Brasileiro de Doença de Chagas9. Os exames foram considerados anormais se apresentassem as seguintes alterações: bloqueio completo do ramo direito, ou incompleto se associado ao hemibloqueio anterior esquerdo; bloqueio do ramo esquerdo; bloqueio atrioventricular de $2^{\circ}$ ou $3^{\circ}$ grau; batimentos ventriculares ectópicos prematuros; taquicardia ventricular não sustentada; bradicardia sinusal < $40 \mathrm{bpm}$ ou pausas sinusais; alterações primárias de segmento ST-T; ondas Q anormais (área eletricamente inativa) ou fibrilação atrial. Os pacientes foram considerados portadores de DNS se apresentassem, ao Holter de 24 horas, os seguintes achados: bradicardia sinusal persistente e inapropriada, pausas sinusais $>3$ segundos, bloqueio sinoatrial, assistolia após a interrupção de taquicardias supraventriculares (síndrome bradi-taqui) ou ritmo juncional ${ }^{15}$. A análise do Holter foi feita duas vezes, em momentos diferentes, por um mesmo observador. A primeira, à medida que se realizavam os exames e, a segunda, quando da coleta de dados para este estudo. 0 uso de fármacos dromo ou cronotrópicos negativos ou hipotensores (como digital, betabloqueador, vasodilatador ou antiarrítmico) 
era interrompido 48 horas antes das avaliações clínicas e laboratoriais. Todos os exames foram analisados de forma independente e cega, por dois observadores, sem conhecimento dos dados clínicos ou de outros métodos complementares. Os dados obtidos no estudo foram utilizados para a criação de um banco de dados do sistema $\mathrm{R}$.

Realizou-se a pesquisa da presença de AcM2 no soro dos pacientes no Laboratório de Eletrofisiologia Cardíaca do Centro de Ciências da Saúde (CCS-UFRJ), pelo registro de seu efeito em corações isolados de coelhos adultos, técnica descrita em detalhes por Farias de Oliveira e cols ${ }^{14}$. 0 protocolo experimental, na primeira etapa, tinha o objetivo de identificar os soros que causavam alterações eletrofisiológicas nos corações perfundidos pela técnica de Langendorff, e consistia de um registro controle de 30 minutos na solução de Tyrode, seguido de, pelo menos, 30 minutos em perfusão na solução contendo Tyrode e soro humano total (diluído 1:100) e, finalmente, lavagem por 30 minutos com a solução de Tyrode. 0 eletrocardiograma era continuamente monitorado e os registros foram feitos a cada cinco minutos, ou quando se observava alteração no ritmo ou na frequiência cardíaca. Os experimentos eram feitos somente se nenhuma alteração significativa no ECG basal era observada por 30 minutos durante o controle. A análise do ECG incluía o registro da frequiência da onda P (frequiência sinusal), da presença de bloqueio na condução intra-atrial, atrioventricular e de outras arritmias. Numa segunda etapa, era realizado o fracionamento do soro total, os testes eram repetidos, para identificar em qual fração se encontrava o fator arritmogênico, e as concentrações de proteína nas frações eram determinadas. Os efeitos das frações que continham ou não as imunoglobulinas $\mathrm{G}$ (IgG+ e IgG-, respectivamente), obtidas do mesmo paciente, eram testados na mesma preparação de coração, com uma lavagem de 30 minutos entre a aplicação de cada uma das frações. 0 grau de purificação do método, usado no fracionamento do soro, era avaliado pela imunodifusão das frações de IgG+ e IgG- contra anticorpos anti-imunoglobulina humana total e anti-imunoglobulina $\mathrm{G}$ humana. $\mathrm{O}$ efeito agonista muscarínico, na resposta a fração IgG+ dos pacientes chagásicos crônicos, era testado pela adição de atropina ao perfusato na preparação do sangue. Definiu-se a presença de AcM2, quando ocorria no experimento in vitro uma diminuição de $10 \%$ na frequiência cardíaca sinusal, em relação ao controle, ou algum grau de bloqueio intra-atrial ou atrioventricular, revertidos após a lavagem do soro.

Os pacientes foram divididos em: grupo I, representado por portadores de DNS e grupo II, de não portadores, sendo estes dois grupos comparados quanto à prevalência de AcM2, idade maior do que 53 anos, sexo masculino, presença de alterações eletrocardiográficas compatíveis com a CCC ${ }^{9}$, disfunção ventricular e clínica de IC. Este estudo foi realizado sob a consultoria estatística da Comissão de Investigação Científica (CIC) do HUCFF/ UFRJ. As variáveis contínuas foram relatadas pela média \pm desvio padrão e as categóricas pelo número absoluto, com o valor percentual entre parênteses. Na análise univariada, para comparação das médias das variáveis numéricas dos grupos I e II foi utilizado o teste "t" de Student. Para comparação das variáveis categóricas foi utilizado o teste Qui-quadrado ou o teste de Fisher, quando necessário. A análise dos dados, para detectar o padrão de dependência entre as variáveis estudadas e o quanto de cada associação era devido à influência dos outros fatores, eliminando o confundimento de efeitos, foi realizada pelo modelo log linear geral ${ }^{48}$.

\section{RESULTADOS}

A amostra estudada da população de chagásicos crônicos constituiu-se de 65 pacientes, já que dos 69 inicialmente selecionados, quatro foram excluídos do estudo pela impossibilidade de localizar a fita do Holter, realizado na mesma época do exame ecocardiográfico. Esta amostra foi dividida em grupo I, composto de 31 (47,7\%) pacientes portadores de DNS, e grupo II, composto de 34 (52,3\%) pacientes não portadores.

A idade (Figura 1 e Tabela 1) mostrou-se equivalente nos dois grupos $(p=0,22)$, mas no grupo I houve predomínio do sexo feminino $(p=0,03)$. Entre os pacientes com 53 anos ou mais, $67,7 \%$ possuíam função ventricular normal e a DNS afetava $58,1 \%$ dos pacientes nesta faixa etária. No entanto, na avaliação dos dados pelo modelo log linear, a idade e o sexo não tiveram qualquer relação com as outras variáveis estudadas. A disfunção ventricular (leve, moderada ou grave) foi muito mais freqüente no grupo I, onde foi diagnosticada em 20 (64,5\%) pacientes, que no grupo II, com quatro (11,8\%) pacientes. A clínica de IC estava presente em $13(41,9 \%)$ pacientes do grupo I, contra somente dois $(5,9 \%)$ pacientes do grupo II. A disfunção do nódulo sinusal estava presente em $83,8 \%$ dos pacientes com algum grau de disfunção ventricular, contra somente $26,8 \%$ daqueles com função normal.

Quanto ao Holter dos pacientes do grupo I, dentre as alterações compatíveis com o diagnóstico de DNS, a bradicardia sinusal inapropriada foi encontrada em 13 (41,9\%) pacientes, seguida do ritmo juncional, em $12(38,7 \%)$, bloqueio sinoatrial em dois $(6,5 \%)$, pausa sinusal em dois $(6,5 \%)$ e síndrome

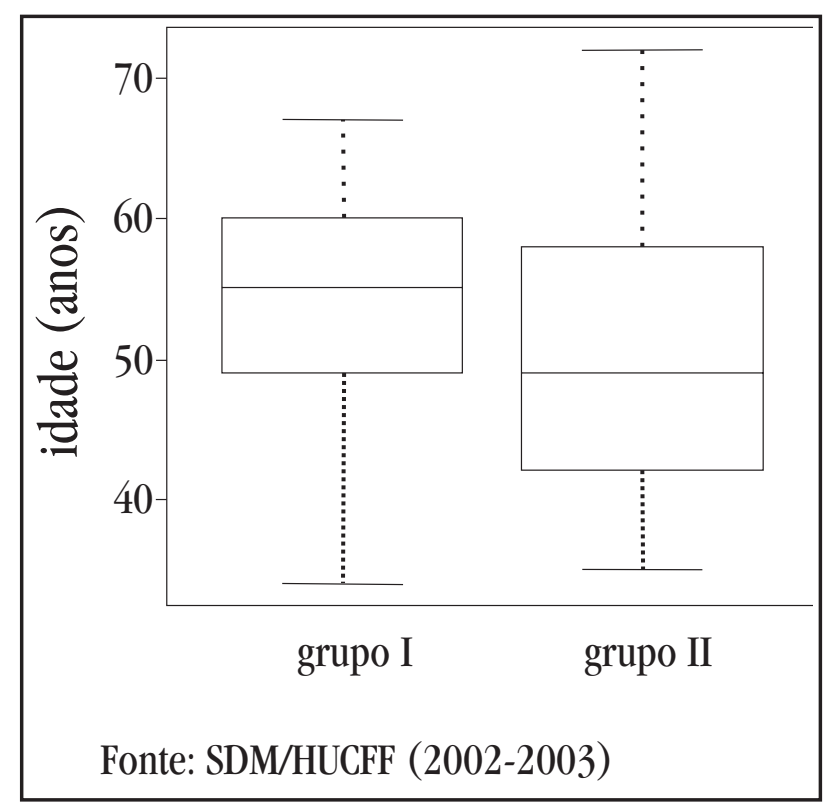

Figura 1 - Distribuição da idade nos grupos I (portadores de disfunção no nódulo sinusal) e II (não portadores). 
Tabela 1 - Características clínicas, eletrocardiográficas e ecocardiográficas dos grupos I (portadores de disfunção do nódulo sinusal) e II (não portadores).

\begin{tabular}{|c|c|c|c|}
\hline Características & Grupo I $\left(\mathrm{n}^{0}=31\right)$ & Grupo II $\left(n^{0}=34\right)$ & Valor $\mathrm{p}$ \\
\hline Idade média (anos) & $53,7 \pm 8,5$ & $50,9 \pm 9,9$ & 0,2248 \\
\hline Sexo feminino & $21(67,7 \%)$ & $16(47,1 \%)$ & 0,0311 \\
\hline Peso (kg) & $62,8 \pm 14,7$ & $69,3 \pm 13,6$ & 0,0729 \\
\hline Altura (m) & $1,59 \pm 0,1$ & $1,63 \pm 0,1$ & 0,1305 \\
\hline Clínica de insuficiência cardíaca & $13(1,9 \%)$ & $2(5,9 \%)$ & $<0,0001$ \\
\hline Uso de medicações cronotrópicas negativas & $16(51,6 \%)$ & $4(11,8 \%)$ & $<0,0001$ \\
\hline beta-bloqueador & $1(3,2 \%)$ & $1(2,9 \%)$ & 1 \\
\hline digital & $6(19,4 \%)$ & $2(5,9 \%)$ & $<0,0001$ \\
\hline amiodarona & $7(22,6 \%)$ & $1(2,9 \%)$ & $<0,0001$ \\
\hline Ecocardiograma alterado & $23(74,2 \%)$ & $7(20,6 \%)$ & $<0,0001$ \\
\hline aumento do DDFVE (>5,5cm) & $15(48,4 \%)$ & $7(20,6 \%)$ & $<0,0001$ \\
\hline disfunção sistólica global do VE & $20(64,5 \%)$ & $4(11,8 \%)$ & $<0,0001$ \\
\hline disfunção sistólica segmentar do VE & $17(54,8 \%)$ & $5(14,7 \%)$ & $<0,0001$ \\
\hline média da FEVE & $49,2 \pm 19,4$ & $65,6 \pm 13,4$ & 0,0002 \\
\hline ECG anormal & $30(96,8 \%)$ & $16(47,1 \%)$ & $<0,0001$ \\
\hline bradicardia sinusal & $4(12,9 \%)$ & $2(5,9 \%)$ & 0,1437 \\
\hline BRD completo isolado & $4(12,9 \%)$ & $4(11,8 \%)$ & 1 \\
\hline HBAE isolado & $2(6,5 \%)$ & $2(5,9 \%)$ & 1 \\
\hline $\mathrm{BRD}+\mathrm{HBAE}$ & $13(41,9 \%)$ & $11(32,4 \%)$ & 0,2491 \\
\hline ESV & $8(25,8 \%)$ & $5(14,7 \%)$ & 0,1429 \\
\hline BRE & $4(12,9 \%)$ & $3(8,8 \%)$ & 0,5435 \\
\hline alterações do segmento ST-T & $3(9,7 \%)$ & $2(5,9 \%)$ & 0,4647 \\
\hline BAV $2^{0}$ grau & $1(3,2 \%)$ & $2(5,9 \%)$ & 0,4647 \\
\hline $\mathrm{BAV} 3^{0}$ grau & $4(12,9 \%)$ & 0 & - \\
\hline AEI (onda q patológica) & $4(12,9 \%)$ & 0 & - \\
\hline fibrilação atrial & $2(6,5 \%)$ & 0 & - \\
\hline taquicardia ventricular & $1(3,2 \%)$ & 0 & - \\
\hline
\end{tabular}

Fonte: SDM-HUCFF/UFRJ (2003-2005)

DDFVE: diâmetro diastólico final de ventrículo esquerdo, VE: ventrículo esquerdo, FEVE: fração de ejeção do ventrículo esquerdo, ECG: eletrocardiograma, BRD: bloqueio de ramo direito, HBAE: hemibloqueio anterior esquerdo, ESV: extrassístole ventricular, BRE: bloqueio de ramo esquerdo, BAV: bloqueio atrioventricular, AEI: área eletricamente inativa.

bradicardia-taquicardia em dois (6,5\%) pacientes. Três pacientes também apresentavam períodos de bloqueio atrioventricular total $(9,7 \%)$, demonstrando a presença de doença binodal.

Sete pacientes do grupo I estavam em uso de amiodarona. No entanto, dois tinham suspendido a medicação, por conta própria, mais de 30 dias antes da realização do Holter, quatro tinham sinais de DNS na monitorização eletrocardiográfica contínua (durante internação no HUCFF ou teste ergométrico) e um tinha bradicardia sinusal sintomática, previamente ao início do uso da droga.

Os AcM2 estavam presentes em 22 (71\%) pacientes do grupo I, contra oito $(23,5 \%)$ pacientes do grupo II, sendo mais prevalente no primeiro em todos os níveis de função ventricular (Figura 2). Embora, à primeira vista, os AcM2 fossem mais freqüentes entre os pacientes com disfunção ventricular, que entre os com função normal (62,5\% versus $36,6 \%$ ), a análise dos dados pelo modelo log linear não mostrou relação direta entre os AcM2 e a disfunção ventricular, somente indireta, através da DNS (Tabela 2 e Figura 3).

Observou-se associação direta significativa (interdependência) entre a DNS e a presença de AcM2 ( $\left.\mathrm{p}=0,0021, \lambda_{\text {Ack2:DSS }}=1,3\right)$, entre a DNS e a disfunção miocárdica ( $\left.\mathrm{p}=0,0005, \lambda_{\text {DNS:DV }}=1,5\right)$ e entre a DNS e a presença de ECG alterado $\left(\mathrm{p}=0,0011, \lambda_{\text {DIS:FCG }}=1,5\right)$. No entanto, a presença de AcM2 foi independente da disfunção ventricular e da clínica de IC, condicionada à disfunção ventricular

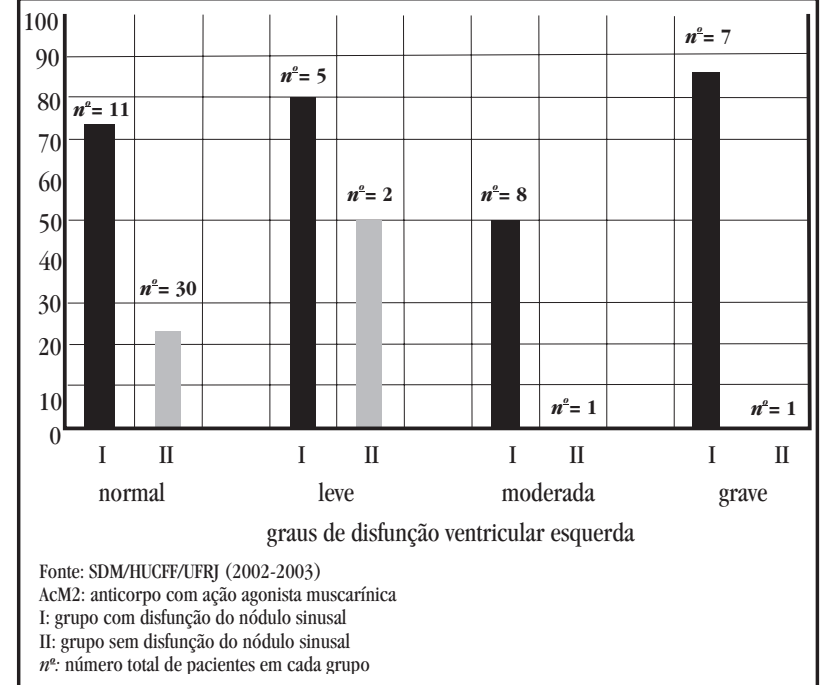

Figura 2 - Prevalência de anticorpos com ação agonista muscarínica nos grupos com e sem DNS (grupos I e II) de acordo com o grau de disfunção ventricular.

(Figura 3). A insuficiência cardíaca só se relacionou com a DNS de forma indireta, por meio da disfunção ventricular ( $\mathrm{p}=0,0001$, $\left.\lambda_{\mathrm{DV}: \mathrm{IC}}=1,9\right)$, isto é, as variáveis IC e DNS são independentes, condicionadas à disfunção ventricular. Já o ECG alterado só se relacionou diretamente com a DNS. 
Tabela 2 - Resultados do modelo log linear para a avaliação da relação entre as variáveis estudadas.

\begin{tabular}{lrrrr}
\hline Variáveis & Estimador $(\lambda)$ & Erro padrão & Valor de $z$ & Valor de p \\
\hline constante & 2,44677 & 0,23886 & 10,244 & $<0,0001$ \\
DNS & $-2,32342$ & 0,48394 & $-4,801$ & $<0,0001$ \\
AcM2 & $-0,75377$ & 0,30317 & $-2,486$ & 0,0129 \\
IC & $-1,81238$ & 0,38132 & $-4,753$ & $<0,0001$ \\
DV & $-1,74589$ & 0,37436 & $-4,664$ & $<0,0001$ \\
ECG & $-0,08004$ & 0,28307 & $-0,283$ & 0,7774 \\
DNS:AcM2 & 1,32176 & 0,42903 & 3,081 & 0,0021 \\
DNS:DV & 1,54045 & 0,44497 & 3,462 & 0,0005 \\
IC:DV & 1,91246 & 0,49564 & 3,859 & 0,0001 \\
DNS:ECG & 1,52040 & 0,46643 & 3,260 & 0,0011 \\
\hline
\end{tabular}

\section{Fonte: SDM-HUCFF/UFRJ (2003-2005)}

DNS: disfunção do nódulo sinusal, AcM2: anticorpo com ação muscarínica, IC: clínica de insuficiência cardíaca, DV: disfunção ventricular, ECG: eletrocardiograma alterado.

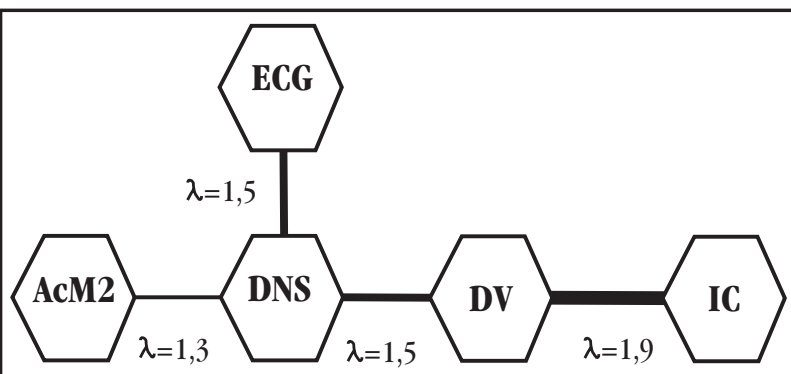

Fonte: SDM/HUCFF/UFRJ (2003-2005)

AcM2: anticorpo com ação agonista muscarínica

DNS: disfunção do nódulo sinusal

DV: difunção ventricular

ECG: eletrocardiograma alterado

IC: clínica de insuficiência cardiaca

Figura 3 - Representação do modelo log linear demonstrando as relações de independência entre as variáveis estudadas. Os valores numéricos $(\lambda)$ correspondem ao estimador da força da relação entre as variáveis.

\section{DISCUSSÃO}

0 dado mais expressivo deste estudo é que pacientes chagásicos crônicos com DNS têm maior prevalência de AcM2, quando comparados aos não portadores de DNS, em qualquer grau de disfunção miocárdica, independentemente da idade e do sexo. No entanto, como este foi um estudo transversal, não foi possível estabelecer relação causal entre os AcM2 e a disfunção nodal e, segundo a literatura, não há provas definitivas de que estes anticorpos sejam responsáveis pelas lesões do sistema de condução, encontradas na CCC ${ }^{2046}$. Só foi possível comprovar que existe, no grupo avaliado, relação de interdependência entre a DNS e a presença de AcM2, e que esta relação foi independente da presença de disfunção ventricular.

A idade avançada e o sexo masculino não influenciaram as outras variáveis, ao contrário de relatos anteriores ${ }^{32130}$. 0 fato dos pacientes estarem afastados da área endêmica há muitos anos, prevenindo reinfecções (o que parece piorar a evolução da $\mathrm{CCC}^{6}$ ), e o estudo ter sido realizado em zona urbana, onde talvez os homens tenham atividades laborativas com menor demanda de esforço físico ${ }^{21}$, pode, talvez, responder por esta diferença.
Ao contrário dos relatos de Pedrosa ${ }^{29}$ e Retondaro e cols ${ }^{32}$, no quais os pacientes portadores de AcM2 tinham maior grau de comprometimento miocárdico (graus de dilatação ventricular), no presente estudo, a prevalência dos AcM2 não se relacionou à disfunção ventricular, a qual só apresentou relação indireta com os anticorpos, através da DNS. Estes dados são compatíveis com os relatos recentes de Ribeiro e cols ${ }^{33}$ e Talvani e cols ${ }^{45}$ e falam contra a hipótese de que os anticorpos sejam consequiência da lesão miocárdica. Não obstante, se não há argumentos que confirmem, definitivamente, a efetiva participação dos AcM2 na patogenia da DNS e da CCC (embora infiram mecanismos semelhantes), tampouco há os que justifiquem sua exclusão. 0 que é inegável é a existência, nos pacientes chagásicos crônicos, de anticorpos circulantes capazes de interagir com a célula cardíaca. Neste contexto, vários trabalhos 1014294142 têm demonstrado, na CCC, a interação de anticorpos de pacientes (e de modelos experimentais) com receptores de neurotransmissores ( $\beta$, M2 e $\alpha 1)$, que modulam o desempenho cardíaco, produzindo mudanças elétricas e mecânicas. A ativação dos receptores muscarínicos diminui a frequiência cardíaca, bloqueia a condução atrioventricular e pode mesmo prolongar o tempo de repolarização ventricular. 0 fato de que $11,3 \%$ da população normal apresenta títulos baixos de anticorpos contra os receptores muscarínicos M2, contribui para tornar a presença destes anticorpos, no soro dos pacientes cardiopatas, menos significativa do ponto de vista da contribuição destes à patogênese da $\mathrm{DNS}^{24}$. Todavia, esta prevalência cai para apenas $1 \%$, quando avaliada a capacidade de interação com 0 receptor em sua conformação nativa ${ }^{19}$.

Os resultados deste estudo permitem a geração de uma hipótese, segundo a qual, em alguns indivíduos com susceptibilidade para o desenvolvimento de autoimunidade, linfócitos T CD4+ reconhecem um epítopo da proteína ribossomal $\mathrm{P}$ do Trypanosoma cruzi, são sensibilizados na periferia e induzem linfócitos B a produzir anticorpos. Devido ao mimetismo molecular, estes também se ligam aos receptores de neurotransmissores muscarínicos M2 e iniciam uma cascata de transdução de sinais intracelulares, culminando com a depressão na eletrogênese cardíaca ${ }^{82937}$. Seria interessante observar se, ao longo do tempo, aqueles pacientes portadores desses AcM2, mas ainda sem DNS, a desenvolverão com mais frequiência do que os não portadores. Se assim fosse, o anticorpo poderia funcionar como um marcador prognóstico.

A disfunção do nódulo sinusal esteve presente em 47,7\% na presente casuística (26,8\% dos pacientes com função ventricular normal e 83,3\% daqueles com disfunção ventricular), prevalência bem maior do que a relatada em outro estudo que utilizou 0 Holter, no qual a DNS foi diagnosticada em 4,5\% dos pacientes oligossintomáticos, e em 36,7\% daqueles com maior grau de lesão miocárdica ${ }^{16}$. Estes dados demonstram que pacientes chagásicos com a forma cardíaca têm alta probabilidade de desenvolvimento de alterações na eletrogênese cardíaca. Levando-se em conta que alguns estudos apontam a DNS como preditor de risco de morte e pior evolução clínica ${ }^{2231}$, estes pacientes devem ser acompanhados mais atentamente. Isto também reforça a necessidade de estudos que contribuam para a compreensão da patogenia da disfunção nodal na CCC, auxiliando no desenvolvimento de novos métodos terapêuticos e preventivos que melhorem a prognóstico da doença. 
Implicações clínicas. Estudos prévios mostraram que o efeito biológico dos AcM2 pode ser neutralizado, in vitro, pelo peptídeo correspondente à sequiência de aminoácidos do seu epítopo funcional no receptor muscarínico, via inibição da interação crônica do anticorpo com o receptor. 0 uso do peptídeo também retirou os anticorpos da circulação e reduziu o número de focos inflamatórios e ninhos do parasita, ligando estes anticorpos com a patogenia da miocardite chagásica ${ }^{1729}{ }^{43}$. Se estes peptídeos também forem capazes de bloquear a ação estimuladora ${ }^{42}$, que estes anticorpos têm sobre os receptores muscarínicos dos linfócitos TCD8+, e supressora, sobre os receptores beta-adrenérgicos dos linfócitos TCD4+, eles poderiam ser utilizados para prevenir ou atenuar a imunodepressão da fase aguda. A melhora da imunidade ajudaria o hospedeiro a realizar a depuração do parasita, controlando seu crescimento e multiplicação e, conseqüientemente, o nível da atividade inflamatória, que, por sua vez, teria papel positivo na melhora da contratilidade miocárdica. A terapia gênica trouxe novas possibilidades de estudo neste campo ${ }^{26}$. No entanto, não se pode excluir a hipótese de que estes AcM2 sejam apenas marcadores da presença da lesão sinusal e do sistema nervoso parassimpático. São necessários estudos prospectivos para comprovar a hipótese de que, anticorpos agonistas de neurorreceptores muscarínicos cardíacos, em pacientes chagásicos crônicos, podem servir como marcadores precoces de risco para o desenvolvimento da DNS extrínseca ou que são responsáveis pelo seu surgimento.

Limitações. Por razões técnicas, o tamanho da amostra da população estudada foi pequeno. No entanto, apesar do número reduzido, a análise dos dados pelo modelo log linear permitiu a avaliação das relações entre as variáveis. Além disso, o número de casos de DNS pode ter sido subdiagnosticado, uma vez que não foi realizado teste ergométrico, estudo eletrofisiológico ou avaliação da frequiência cardíaca intrínseca nos pacientes, embora a sensibilidade do Holter seja maior do que a destes exames para o diagnóstico de $\mathrm{DNS}^{4}{ }^{44}$. Desse modo, também, não foi possível separar aqueles com DNS intrínseca daqueles com disfunção extrínseca, o que pode explicar o maior número de pacientes com DNS nos subgrupos com disfunção ventricular e cardiomegalia. A associação entre a disfunção sinusal e a ventricular já foi relatada por outros ${ }^{112840}$ e era esperada, pois no grupo I estão incluídos pacientes tanto com disfunção sinusal extrínseca quanto intrínseca. Nestes últimos, a DNS provavelmente está relacionada à lesão miocárdica (secundária à miocardite chagásica crônica). Logo, aqueles com cardiopatia mais avançada estariam mais propensos à destruição simultânea do tecido sinusal.

Como era necessário avaliar o estado da função ventricular na época em que foi realizado o Holter e a pesquisa da presença dos AcM2, foi preciso utilizar, como fonte de dados, ecocardiogramas cujas fitas e laudos se encontravam no SMD e prontuários dos pacientes. Desse modo, estes exames não foram realizados por uma mesma pessoa, nem padronizados para o estudo, podendo sofrer pequenas variações de técnica.

\section{REFERÊNCIAS}

1. Álvares JM. Bradiarritmias. In: Cançado JR, Chuster M (eds) Cardiopatia Chagásica, $1^{a}$ edição, Fundação Carlos Chagas, Belo Horizonte, p. 266-273, 1985.
2. Amico AF, Lichtenberg GS, Reisner AS, Stone CK, Schwartz RG, Meltzer RS Superiority of visual versus computerized echocardiographic estimation of radionuclide left ventricular ejection fraction. American Heart Journal 118: 1259-1265, 1989.

3. Baruffa G, Alcântara Filho A, Aquino Neto JO. Estudo pareado da cardiopatia chagásica no Rio Grande do Sul. Brasil. Memórias do Instituto Oswaldo Cruz 80: 457-463, 1985.

4. Boudoulas H, Schaal SF, Lewis RP, Robinson JL. Superiority of 24-hour outpatient monitoring over multi-stage exercise testing for the evaluation of syncope. Journal of Electrocardiology 12: 103-108, 1979.

5. Bradford MM. A rapid and sensitive method for the quantitation of microgram quantities of protein utilizing the principle of protein-dye binding. Analytical Biochemistry 72: 248-254, 1976.

6. Bustamente JM, Rivarola HW, Fernandez AR. Indeterminate Chagas' disease: Trypanosoma cruzi and re-infection are factors involved in the progression of cardiopathy. Clinical Science 104: 415-420, 2003.

7. Campos-de-Carvalho A, Masuda MO, Tanowitz HB, Wittner M, Goldenberg RC, Spray DC. Conduction defects and arrythmias in Chagas Disease: Possible role of gap junctions and humoral mechanisms. Journal of Cardiovascular Electrophysiology 5: 686-698, 1994.

8. Campos-de-Carvalho AC, Levin M, Oliveira SF, Nascimento JHM, Pedrosa RC, López Bergami P, Ferrari I, Masuda MO. Possible involvement of anti-ribosomal $T$. cruz $i \mathrm{P}$ protein in the cardiac disturbances of chronic Chagas' disease. Memórias do Instituto Oswaldo Cruz 90 (supl I): 151, 1995.

9. Consenso brasileiro em doença de Chagas. Revista da Sociedade Brasileira de Medicina Tropical 38 (supl III): 1-29, 2005.

10. Costa PC, Fortes FS, Machado AB, Almeida NA, Olivares EL, Cabral PR, Pedrosa RC, Goldenberg RC, Campos-De-Carvalho AC, Masuda MO. Sera from chronic chagasic patients depress cardiac electrogenesis and conduction. Brazilian Journal of Medical Biology Research 33: 439-446, 2000.

11. Dávila DF, Donis, JH, Navas M, Feunmayor AJ, Torres A, Gottberg C. Response of heart rate to atropine and left ventricular function in Chagas' heart disease. International Journal of Cardiology 21: 143-156, 1988.

12. Diretrizes éticas internacionais para pesquisas biomédicas envolvendo seres humanos (CIOMS/OMS). Bioética 3: 95-134, 1995.

13. Farias-de-Oliveira S, Pedrosa RC, Nascimento JHMS, Carvalho ACC, Masuda MO. Depression of cardiac automaticity and A-V conduction by IgG fraction of chronic chagasic patients with arrhythmia is mediated by muscarinic receptors. Memórias do Instituto Oswaldo Cruz 90 (supl I): 151, 1995.

14. Farias-de-Oliveira S, Pedrosa RC, Nascimento JHM, Carvalho ACC, Masuda MO. Sera from chronic Chagasic patients with complex cardiac arrhythmias depress electrogenesis and conduction in isolated rabbit hearts. Circulation 96: 20312037, 1997.

15. Ferrer MI. The sick sinus syndrome. Circulation 47: 635-641, 1973.

16. Gizzi JC, Vergara G, Kormann DS, Jatene AD, Sousa JEMR. 0 sistema de condução na doença de Chagas. Arquivos Brasileiros de Cardiologia 29 (supl I): 234-235, 1976.

17. Goin JC, Leiros CP, Borda E, Sterin-Borda L. Interaction of human chagasic IgG with the second extracelular loop of the human heart muscarinic acetylcholine receptor: functional and pathological implications. The Federation of American Societies for Experimental Biology Journal 10: 77-83, 1997.

18. Hernandez CC, Barcellos LC, Gimenez LE, Cabarcas RA, Garcia S, Pedrosa RC, Nascimento JH, Kurtenbach E, Masuda MO, Carvalho ACC. Human chagasic IgGs bind to cardiac muscarinic receptors and impair L-type Ca2+ currents. Cardiovascular Research 58: 55-65, 2003.

19. Jahns R, Boivin V, Siegmund C, Inselmann G, Lohse MJ, Boege F. Autoantibodies activating human $\beta_{1}$-adrenergic receptors are associated with reduced cardiac function in chronic heart failure. Circulation 99: 649-654, 1999.

20. Kierszenbaum F. Where do we stand on the autoimmunity hypotheses of Chagas' disease? Trends in Parasitology 21: 513-516, 2005.

21. Köberle F. Cardiopatia chagásica. O Hospital 53: 311-346, 1958.

22. Laranja FS, Dias E, Nobrega G, Miranda A. Chagas' disease. A clinical, epidemiologic, and pathologic study. Circulation 14: 1035-1060, 1956.

23. Liu HR, Zhao RR, Jiao X, Wang Y, Fu M. Relationship of myocardial remodeling to the genesis of serum autoantibodies to cardiac beta1-adrenoceptors and 
muscarinic type 2 acetylcholine receptors in rats. Journal of the American College of Cardiology 39: 1866-1873, 2002.

24. Liu HR, Zhao RR, Zhi JM, Wu BW, Fu ML. Screening of serum autoantibodies to cardiac beta1-adrenoceptors and M2-muscarinic acetylcholine receptors in 408 healthy subjects of varying ages. Autoimmunity 29: 43-51, 1999.

25. Maguire JH, Mott KE, Souza JA, Almeida EC, Ramos NB, Guimarães AC. Electrocardiographic classification and abbreviated lead system for populationbased studies of Chagas' disease. Bullettin of Pan American Health Organization 16: 47-58, 1982.

26. Medin JA, Buttrick PM. Gene transfer in the cardiovascular system: update 2000. Heart Disease 2: 409-421, 2000.

27. Palmero HA, Caeiro TF, Iosa DJ. Effect of Chagas' disease on arterial blood pressure. American Heart Journal 97: 38-42, 1979.

28. Palmero HA, Caeiro TF, Iosa DJ. Prevalence of slow heart rate in chronic Chagas' disease. The American Journal of Tropical Medicine and Hygiene 30: 1179-1182, 1981.

29. Pedrosa RC. Contribuição ao estudo da etiopatogenia do distúrbio de condução e da eletrogênese na cardiopatia chagásica crônica: efeitos de anticorpos IgG de pacientes chagásicos crônicos na eletrogênese e no sistema de condução do coração isolado de mamíferos. Tese de Doutorado, Universidade Federal do Rio de Janeiro, Rio de Janeiro, RJ, 1998.

30. Pugliese C, Lessa I. Estudo da sobrevida na miocardite crônica de Chagas descompensada. Revista do Instituto de Medicina Tropical de São Paulo 18: 191-201, 1976

31. Rassi Jr A, Rassi SG, Rassi A. Morte súbita na doença de Chagas. Arquivos Brasileiros de Cardiologia 76: 86-96, 2001.

32. Retondaro FC, Costa PCS, Pedrosa RC, Kurtenbach E. Presence of antibodies against the third intracellular loop of the $\mathrm{m} 2$ muscarinic receptor in the sera of chronic chagasic patients. The Federation of American Societies for Experimental Biology Journal 13: 2015-2020, 1999.

33. Ribeiro, ALP, Gimenez LED, Hernández CCQ, Carvalho ACC, Teixeira MM, Guedes VC, Barros MVL, Lombardi F, Rocha MOC. Early occurrence of anti-muscarinic autoantibodies and abnormal vagal modulation in Chagas disease. International Journal of Cardiology 117: 59-63, 2007.

34. Ribeiro ALP, Moraes RS, Ribeiro JP, Ferlin EL, Torres RM, Oliveira E, Rocha MO. Parasympathetic dysautonomia precedes left ventricular systolic dysfunction in Chagas' disease. American Heart Journal 141: 260-265, 2001.

35. Rose GA, Blackburn H. Cardiovascular survey methods. World Health Organization Monograph Series 56: 1-188, 1982.
36. Sahn DJ, DeMaria A, Kisslo J, Weyman A. Recommendations regarding quantitation in m-mode echocardiography: results of a survey of echocardiographic measurements. Circulation 58: 1072-1083, 1978.

37. Schmuñis GA. Autoimmunity in Chagas' disease. Memórias do Instituto Oswaldo Cruz 82: 287-310, 1987

38. Schmuñis GA. A tripanossomíase americana e seu impacto na saúde pública das Américas. In: Brener Z, andrade ZA, Barral-Neto M (eds) Trypanosoma cruzi a doença de Chagas, $2^{\mathrm{a}}$ edição, Guanabara Koogan, Rio de Janeiro, p.1-15, 2000.

39. Schocken DD, Arrieta MI, Leaverton, Ross EA. Prevalence and mortality rate of congestive heart failure in the United States. Journal of the American College of Cardiology 20: 301-306, 1992.

40. Sgammini H. Estado actual del tratamiento antiarrítmico en el paciente con enfermedad de Chagas. In: $2^{\circ}$ Simposio Virtual de Enfermedad de Chagas, 2002 Mesa de debate $\mathrm{n}^{\circ}$ 5: Avances em Tratamiento de complicaciones. Disponível em: http://www.fac.org.ar/fec/chagas2/llave/md5/md507/sgam.htm. Acesso em: 22 ago, 2005.

41. Sterin-Borda L, Borda E. Role of neurotransmitter autoantibodies in the pathogenesis of chagasic peripheral disautonomia. Annals of New York Academy of Science 917: 273-280, 2000

42. Sterin-Borda L, Gorelik G, Genaro A, Goin JC, Borda ES. Human chagasic IgG interacting with lymphocyte neurotransmitter receptors triggers intracellular signal transduction. The Federation of American Societies for Experimental Biology Journal 4: 1661-1667, 1990.

43. Sterin-Borda L, Joensen L, Bayo-Hanza C, Esteva M, Borda E. Therapeutic use of muscarinic acetylcholine receptor peptide to prevent mice chagasic dysfunction. Journal of Molecular and Cellular Cardiology 34: 1645-1654, 2002.

44. Szátmary L, Jouve A, Pinot JJ, Torresani J. Comparative study of electrophysiological and holter monitoring data in estimating sinoatrial function. Cardiology 70: $184-193,1983$.

45. Talvani A, Rocha MOC, Ribeiro AL, Borda E, Sterin-Borda L, Teixeira MM. Levels of anti- $M_{2}$ and anti- $\beta_{1}$ autoantibodies do not correlate with the degree of heart dysfunction in Chagas' heart disease. Microbes Infection 8: 2459-2464, 2006.

46. Tarleton RL, Zhang L. Chagas' disease etiology: Autoimmunity or parasite persistence? Parasitology Today 15: 94-99, 1999.

47. Teichholz LE, Kreulen T, Herman MV, Gorlin R. Problems in echocardiographic volume determinations: echocardiographic-angiographic correlations in the presence of absence of asynergy. American Journal of Cardiology 37: 7-11, 1976.

48. Tura BR. Aplicação do "Data Mining” em medicina. Tese de Mestrado, Universidade Federal do Rio de Janeiro, Rio de Janeiro, RJ, 2001 